\title{
HERMENÊUTICA NA EDUCAÇÃO: UM MÉTODO PARA A COMPREENSÃO DA REALIDADE EDUCACIONAL
}

\author{
Karina Augusta Limonta Vieira ${ }^{1}$
}

\begin{abstract}
Resumo:
Este artigo tem o objetivo de apresentar e discutir, de maneira original, a base teórica e epistemológica da hermenêutica como método, levando em consideração as dimensões educacionais e a compreensão da realidade educacional, bem como o seu possível uso metodológico e metódico. O artigo tem como questões norteadoras: Qual é o campo de pesquisa da hermenêutica? Quais são as bases epistemológicas e teóricas da hermenêutica? Qual é a importância da hermenêutica para a compreensão da realidade educacional? Para atingir o objetivo e responder as problemáticas, realiza-se uma revisão da literatura alemã sobre hermenêutica na educação, a fim de apresentar a hermenêutica como possibilidade metodológica e metódica e construir uma contextualização desse método na área da educação. Esse método é fundamental para estruturar novos sentidos para ação educativa e para o campo da pesquisa em educação.
\end{abstract}

Palavras-chave: Método. Hermenêutica. Educação.

\footnotetext{
1 Doutora em Educação Escolar pelo Programa de Pós-Graduação em Educação Escolar na UNESP - Universidade Estadual Paulista com estágio doutoral na Universidade Livre de Berlim. Mestre em Educação Escolar e Graduada em Pedagogia pela UNESP - Universidade Estadual Paulista. Docente na UEMG - Universidade do Estado de Minas Gerais. Pesquisadora Associada da Universidade Livre de Berlim na área de Antropologia da Educação.

E-mail: kalimonta@gmail.com
} 


\title{
HERMENEUTIC IN EDUCATION: A METHOD FOR UNDERSTANDING EDUCATIONAL REALITY
}

\author{
Karina Augusta Limonta Vieira
}

\begin{abstract}
:
This paper aims at showing and discussing of original way the theoretical and epistemological foundations of hermeneutic like a method, taking educational dimensions and understanding of educational reality, as well its possible methodological and methodical application. This paper puts following questions: which is research field of hermeneutic? Which are theoretical and epistemological foundations of hermeneutic? What is importance of hermeneutic to understanding of educational reality? To reach aim and to answer the questions, this paper performs a German literature review about hermeneutic in education in order to show hermeneutic like methodological and methodical possibility and a context structure of that method in education field. That method is fundamental to structure new senses for educative action and research in education field.
\end{abstract}

Keywords: Method. Hermeneutic. Education. 


\section{Introdução}

A hermenêutica é um método cujo campo de atuação envolve a compreensão da dinamicidade e da profundidade dos aspectos subjetivos e objetivos do problema de pesquisa. Hoje, esse método compreende um vasto campo de diferentes objetivos e posições filosóficas, assim como diferentes métodos de interpretação. É um método que parte da compreensão da realidade e de tudo o que é humano. É definido como a arte da interpretação de compreender o texto, que ocorre num movimento circular, envolvendo tanto o lado objetivo, quanto o subjetivo. O conceito central da hermenêutica é a "compreensão" em que os conceitos "compreensão", "espírito objetivo" e "círculo hermenêutico" estão intimamente ligados. No entanto, é preciso ter consciência de que a hermenêutica é apenas um "método", apenas um entre outros métodos.

A hermenêutica parte da interpretação e compreensão da realidade e esse método, como aliado das ciências da educação, amplia a visão sobre o fenômeno educacional. O específico de uma hermenêutica na educação encontra-se no sentido da educação e isso a distingue da hermenêutica geral e de outros métodos, porque ela não parte de condições fixas, mas pressupõe e inclui tudo o que é humano na educação. A realidade educacional é constituída e construída de inúmeras facetas que demarcam o seu cotidiano e as relações entre as pessoas.

A responsabilidade principal da hermenêutica na educação consiste no entendimento preliminar da educação prática e teórica, ou seja, o sentido da educação. Por isso, compreende a individualidade das pessoas envolvidas na educação, o significado das realidades educacionais, a responsabilidade da educação e as dimensões educacionais são pontos importantes desse método, enfatiza Danner (2006). Nesse sentido, este artigo tem o objetivo de apresentar e discutir, de maneira original, a base teórica e epistemológica da hermenêutica como método, levando em consideração as dimensões educacionais e a compreensão da realidade educacional, bem como o seu possível uso metodológico e metódico. O artigo tem como questões norteadoras: Qual é o campo de pesquisa da Hermenêutica? Quais são as bases epistemológicas e teóricas da Hermenêutica? Qual é a importância da Hermenêutica para a compreensão da realidade educacional? Para atingir o objetivo e responder as problemáticas, realiza-se uma revisão da literatura alemã (MAYRING, 2002) sobre hermenêutica na educação, a fim de apresentar a hermenêutica como possibilidade metodológica e metódica e construir uma contextualização desse método na área da educação.

Esse método traz para a área da Educação a possibilidade de compreensão da realidade educacional, por meio de reflexões sobre o sentido educacional, entendimento e compreensão do mundo educacional. Neste artigo são, então, desenvolvidos os seguintes tópicos: a Pesquisa Qualitativa, a Hermenêutica, a Hermenêutica na Educação

e a Hermenêutica e as dimensões educacionais na formação humana. É interessante explicitar que a compreensão da realidade educacional leva à construção de novos 
sentidos para a ação educativa e para a pesquisa em educação.

\section{Pesquisa qualitativa}

O campo da hermenêutica é o da pesquisa qualitativa. Faz-se necessário, neste momento, apenas situar a pesquisa qualitativa como forma de entendimento e da colocação da hermenêutica no cenário da pesquisa. Aqui, são apresentados os pressupostos teóricos básicos e as características da prática da pesquisa qualitativa. A pesquisa qualitativa subsidia esse método e é importante para compreender a sua dinamicidade, abertura e profundidade e, principalmente, porque está atenta aos detalhes e prioriza os aspectos subjetivos do problema. Isso quer dizer que ela é capaz de identificar e analisar dados que não são mensurados, mas priorizam dados oriundos de observações, entrevistas, grupos focais, videografias, entre outros, que são apresentados por meio de relatórios que focam o ponto de vista dos sujeitos e suas subjetividades.

Para a explicitação dos pressupostos teóricos básicos e as características da pesquisa qualitativa, são utilizados os seguintes materiais teóricos: o What is Qualitative Research? An Introduction to the Field, de Uwe Flick, Ernst von Kardorff e Ines Steinke, e Mapping the Field, de Uwe Flick, como suportes para a breve explicitação da pesquisa qualitativa.

É importante iniciar este tópico argumentando que a pesquisa qualitativa não retrata apenas a realidade, mas promove o autorreconhecimento do pesquisador:

\footnotetext{
[...] com suas descrições precisas e "grossas", não simplesmente retratam a realidade, nem praticam exotismo para seu próprio bem. É algo que faz uso do incomum, do desviante e do inesperado como fonte de uma visão e um espelho, cuja reflexão faz com que o desconhecido seja perceptível no conhecido, e o conhecido perceptível no desconhecido, abrindo novas possibilidades para o (auto) reconhecimento (FLICK; KARDOFF; STEINKE, 2004, p.03, tradução nossa)
}

A maneira de abordar os fenômenos colocados sob investigação, por meio da abertura para o desconhecido, indica a relevância da pesquisa qualitativa. Flick, Kardoff e Steinke (2004) explicam que esse tipo de pesquisa é, com frequência, mais aberta, quando o desconhecido do novo material de pesquisa é aproximado e familiarizado. Desse modo, ocorre a abertura para o mundo da experiência, logo, o seu projeto interno e os princípios de sua construção não são apenas um fim em si, que dá um panorama de “instantâneos culturais” de pequenos mundos da vida, mas é, também, o principal ponto de partida para a construção de uma base teórica.

As abordagens teóricas da pesquisa qualitativa podem se basear, resumidamente, em três grandes grupos: primeiro, nas tradições do interacionismo simbólico e da fenomenologia que tendem a buscar significados subjetivos e atribuições de sentidos 
individuais; segundo, em etnometodologia e construtivismo interessado na rotina diária e na construção da realidade social. Um terceiro ponto de referência encontrase em posições estruturalistas ou psicanalíticas que procedem de um pressuposto de configurações sociais latentes e de estruturas e mecanismos psíquicos inconscientes. É importante frisar que essas diferentes abordagens da pesquisa apresentam diferenças quanto aos seus pressupostos teóricos, sua compreensão do objeto de investigação e o seu enfoque metódico.

Essas abordagens também diferem em seus objetivos de pesquisa e nos métodos que elas aplicam. O primeiro grupo constrasta a "visão do sujeito" que está em primeiro plano. O segundo grupo tem como objetivo descrever os processos envolvidos na construção de situações sociais existentes, como o institucional ou, simplesmente, o social e a ordem social, explica Flick, Kardoff e Steinke (2004). E, em grande parte, a reconstrução hermenêutica da ação e do significado de geração das estruturas profundas, de acordo com as ideias psicanalíticas ou a hermenêutica-objetiva, são características do terceiro tipo de perspectiva da investigação.

Segundo Flick, Kardoff e Steinke (2004, p. 5, tradução nossa) existem diferentes perspectivas da Pesquisa Qualitativa com suas posições teóricas, métodos de coleta de dados, métodos de interpretação e campos de aplicação.

- Modos de acesso a pontos de vista subjetivos tendo as seguintes posições teóricas: interacionismo simbólico e hermenêutica. Seus métodos de coleta de dados são: Entrevista semi-estruturada e Entrevista narrativa. Os métodos de interpretação são: codificação teórica, análise de conteúdo qualitativa, análise narrativa e procedimentos hermenêuticos. Essa perspectiva pode ser aplicada à pesquisa biográfica e à análise do conhecimento do dia-a-dia.

- Descrição do processo de criação de situações sociais. As posições teóricas que se encontram nessa perspectiva são: a etnometodologia e o construtivismo. Seus métodos de coleta de dados são: o grupo focal, a etnografia, a observação participante, a gravação das interações e a coleta de documentos. Os métodos de interpretação dessa perspectiva são: análise de conversação, análise do discurso, análise de gênero e análise de documento. Essa perspectiva pode ser aplicada aos seguintes campos: análise do mundo da vida e organizações, avaliação da pesquisa e estudos culturais.

- Análise Hermenêutica de estruturas subjacentes. Encontram-se, nessa perspectiva, as seguintes posições teóricas: psicanálise, estruturalismo genético, gravação de interações, fotografia e filmes. Os métodos de coleta são: gravação de interações, fotografia e filmes. Os métodos de interpretação são: hermenêutica objetiva, hermenêutica da estrutura profunda e hermenêutica sociológica do conhecimento. E essa perspectiva pode ser aplicada aos campos da pesquisa familiar, da pesquisa biográfica, da pesquisa de gerações e da pesquisa de gênero. 
Flick, Kardoff e Steinke (2004) explicam que os métodos de recolha e processamento de dados podem ser atribuídos a essas perspectivas de investigação da seguinte maneira: no primeiro grupo, entrevistas narrativas guiadas e processos relacionados de codificação ou análise de conteúdo estão em primeiro plano. Na segunda perspectiva da pesquisa, os dados tendem a ser recolhidos em grupos focais, através de métodos etnográficos ou de observação (participante) e por meio de gravação de mídia das interações para que elas possam, então, ser avaliadas a partir do discurso ou da análise de conversação. Pode incluir, também, as abordagens de gênero e a análise de documentos. Representantes da terceira perspectiva coletam dados, principalmente, através da gravação das interações e do uso de fotos e filmes, que são sempre atribuídos a uma das várias formas de análise hermenêutica. Além dos pressupostos teóricos, há os pressupostos básicos da pesquisa qualitativa.

A pesquisa qualitativa é guiada por quatro pressupostos básicos, de acordo com Flick, Kardoff e Steinke (2004, p. 6, tradução nossa):

1- A realidade social é entendida como um produto e atribuição de significados compartilhados;

2 - A natureza processual e a reflexividade da realidade social são assumidas;

3 - As circunstâncias de vida objetivas são relevantes para um mundo da vida através de significados subjetivos;

4 - A natureza comunicativa da realidade social permite a reconstrução das instalações da realidade social para se tornar o ponto de partida para a investigação.

Em toda a heterogeneidade das abordagens da pesquisa qualitativa, os pressupostos básicos e as características da prática são comuns a todos elas, de maneira que se completam e se interconectam.

As características da prática da pesquisa qualitativa são as seguintes (FLICK, KARDOFF; STEINKE, 2004, p. 6, tradução nossa):

1 - Variedade de métodos em vez de um único método;

2 - Adequação dos métodos;

3 - Orientação para eventos diários e/ou conhecimento cotidiano;

4 - Contextualidade como um princípio orientador;

5 - Perspectivas de participantes;

6 - Capacidade reflexiva do investigador;

7 - Entender o princípio da descoberta;

8 - Princípio da abertura;

9 - Análise de caso como ponto de partida;

10 - Construção da realidade como base; 
11 - A pesquisa qualitativa como uma disciplina textual;

12 - Descoberta e formação de teorias como meta.

Os pressupostos teóricos básicos e as características da pesquisa qualitativa se completam e se interconectam para a compreensão do objeto de investigação, de acordo com o enfoque metodológico definido e a visão subjetiva do pesquisador. A pesquisa qualitativa, então, aproxima e familiariza o pesquisador com o seu objeto. A abertura para o mundo da experiência da pesquisa qualitativa é a abordagem para a realização de pesquisas na área da educação.

\section{Hermenêutica}

A hermenêutica, hoje, como pontua Weller (2007), compreende um vasto campo de diferentes objetivos e posições filosóficas, assim como diferentes métodos de interpretação de textos inspirados em teóricos, tais como Schleiermacher (1768-1834), Dilthey (1833-1911), Weber (1864-1920), Mannheim (1893-1947), Heidegger (18891976), Gadamer (1900-2002), Habermas (1929-) e Ricœur (1913-2005).

Hermenêutica é um método utilizado para interpretar o sentido da palavra do autor. O termo "hermenêutica" remete ao deus grego Hermes, o mensageiro dos deuses. Sendo assim, o hermeneuta seria tanto aquele que transmite quanto o que interpreta uma mensagem. Para Dilthey (1989), a pergunta fundamental da hermenêutica é: como é possível compreender? Ou seja, o que me torna capaz de compreender o que o outro disse? Nas ciências humanas, é a vivência do sujeito que permite atribuir significado aos acontecimentos.

A hermenêutica, como método para a compreensão da realidade educacional, exige, a princípio, o entendimento dos elementos constituintes da hermenêutica. Esses elementos são os seguintes: a Hermenêutica como a arte de compreender e os Conceitos básicos da Hermenêutica. Esses elementos evidenciam o significado da hermenêutica para além da noção de interpretação de texto, envolvendo conceitos como compreensão, espírito objetivo e o círculo hermenêutico, mostrando que a hermenêutica é a arte da interpretação da compreensão do texto que ocorre num movimento circular, envolvendo tanto o lado objetivo quanto o subjetivo. Esses elementos abrem horizontes, pois estão em constante movimento circular, no qual se envolvem teoria, ação, reflexão e o mundo da vida.

\section{- Hermenêutica como a arte de compreender}

Hermenêutica como definição da investigação é reportada à origem da palavra grega hermeneuein, isto é, a arte manifesta, interpretada, explicada e exposta, segundo Hans-Georg Gadamer (1998), representante da hermenêutica filosófica. Danner (2006) amplia e explicita que a palavra "hermenêutica” tem três significados: declarações 
(expresso), interpretação (explicar) e tradução (interpretação). Esses três significados básicos são subjacentes e algo deve ser levado em consideração na hermenêutica, como, por exemplo, "se eu expresso uma situação, eu quero que os outros entendam isso. O falado, por sua vez, é para ser entendido por outra pessoa, de modo que seja interpretado e compreendido.” (DANNER, 2006, p. 34, tradução nossa).

Originalmente, Hermenêutica significa, então, a Interpretação do Sentido do Texto, explica Rittelmeyer e Parmentier (2006). As perguntas para abordar o sentido do texto são: $\mathrm{O}$ que os autores acreditam, o que eles dizem ou escrevem? O que significa o texto? Qual a realidade em que os autores estão situados, social e historicamente? O que motiva os autores e escritores para determinadas observações, formulações e regras do projeto no texto em formação? Mas muito além daquilo que é escrito sobre hermenêutica, Danner (2006) chama a atenção para a questão da compreensão. A hermenêutica envolve interpretação, mas também envolve a compreensão sobre o seu autor e o entorno de seu histórico. Diemer (apud DANNER, 2006, p. 35) dá a seguinte definição: “A hermenêutica é uma disciplina teórica (filosófica) que examina a compreensão do fenômeno, seus elementos, estruturas, tipos, etc., bem como seu contexto pré-existente."

Danner (2006) coloca que, ao contrário do que muitos pensam, a hermenêutica é mais que uma arte da intepretação, é a "arte da interpretação" de compreender. O termo "arte" ressoa com as associações que ocultam o verdadeiro sentido e, nesse caso, $a$ "arte" é entendida de modo muito mais sóbrio, ou seja, diante do conceito grego de techné. Hermenêutica é hermeneutiké techné. Esse termo representa a habilidade e o conhecimento, isto é, o desenvolvimento de uma habilidade.

Se a hermenêutica é a "arte da interpretação de compreender", então pergunte a si mesmo o que pode ser, de alguma maneira, interpretado e compreendido, pontua Danner (2006). Frequentemente, hermenêutica é restrita à interpretação de texto, embora este seja um campo importante e amplo. No entanto, a compreensão do significado hermenêutico não se estende apenas aos textos. Em vez disso, podemos dizer, em geral e antecipadamente, que nós sempre utilizamos a abordagem hermenêutica quando lidamos com as pessoas e com os produtos humanos, no sentido lato, afirma Danner (2006). Como se pode ver, as investigações hermenêuticas já não refletem, hoje, apenas textos, explica Rittelmeyer (2013), mas lidam também, de maneira mais ampla, com os fenômenos do mundo da vida, na medida em que eles se nos apresentam incompreensíveis ou enigmáticos.

\section{- Conceitos básicos da hermenêutica}

Os conceitos da hermenêutica são quatro: a compreensão, a responsabilidade da compreensão, o círculo hermenêutico e as regras da hermenêutica. Esses conceitos complementam-se no decorrer da pesquisa hermenêutica e da interpretação e 
compreensão do texto.

\section{a) A compreensão}

O conceito central da hermenêutica é a “compreensão”. Segundo Danner (2006), nós compreendemos como outras pessoas falam uns com os outros, leem cartazes, ouvem música ou seguem uma palestra. Constantemente compreendemos os gestos dos outros, as suas palavras, o convite da publicidade, uma música ou um contexto espiritual. Mas acontece que um gesto não é precisamente “compreendido”, mas apenas "explicado” por meio dos movimentos corporais do braço e mão, da força muscular e do consumo de energia.

E há diferença entre explicar (erklären) e compreender (verstehen). Segundo Dilthey (1961) compreensão não é um processo imediato, irrefletido, como a explicação, mas deve ser refletida em sua estrutura, no seu desempenho e na sua complexidade. É um processo de reflexão, e não uma forma imediata. A distinção entre “explicação” e “compreensão” é a tentativa de definição para manter duas questões separadas, explica Danner (2006), pois, coloquialmente, a palavra “compreender” tem muitas operações. “Compreensão”, no sentido hermenêutico, é um termo técnico. Esquematicamente, a “compreensão” e a "explicação” são distinguidos do uso coloquial e diferenciado em si.

Segundo Danner (2006), compreensão é o reconhecimento de algo como próprio do humano: todos os sons que eu reconheço como palavras e seus significados são detectados. Explicação, no entanto, é o fato decorrente de causas que derivam de uma condição, de um princípio, como, por exemplo, a explicação da queda de uma pedra.

A compreensão, de acordo com Danner (2006), pode distinguir os seguintes elementos estruturais:

1. Nós identificamos uma coisa, uma operação verdadeira, sensorial.

2. Reconhecemos isto ou aquilo como algo humano.

3. Nós entendemos, reflexivamente, a sua importância, o significado do Humano.

Todo esse processo se dá em uma unidade que chamamos de compreensão.

Finalmente, salienta Danner (2006), o conceito hermenêutico de compreensão está direcionado para o humano (intelectual), especificamente, sobre ações, estruturas linguísticas e entidades não linguísticas. Além do mais, o que foi identificado na ação sensorial e que tenha sido percebido como importante é objeto de reflexão e, então, é compreendido, criando um significado.

\section{b) A responsabilidade da compreensão}

De acordo com Danner (2006), compreensão é a compreensão do “espírito objetivo”. 
Este é o denominador comum de uma área cultural determinada historicamente e é de onde vem cada assunto proporcional do "espírito objetivo”, sendo comum a soma das características comuns do sentido dado que poderiam causar a compreensão mútua, tanto razoável quanto possível. Os sentidos são realmente dados a nós como indivíduos, mas histórica e sócio-culturalmente condicionados, não a priori, como alguns sentidos “absolutos”.

A responsabilidade da compreensão hermenêutica pode ser vista entre dois extremos: entre a subjetividade (evitável), por um lado, que é determinada pela arbitrariedade aleatória e de simples auto-consciência e é vista em um nível puramente psicológico, e do outro, a generalidade, face a um ideal científico em que qualquer declaração esteja acessível em todos os momentos. Ambas as opções são regidas pela hermenêutica. (DANNER, 2006, p.60, tradução nossa)

Dessa forma, o significado é baseado na comunhão do “espírito objetivo”, que é histórica e culturalmente condicionado, e a subjetividade.

\section{c) O círculo hermenêutico}

Se a maior compreensão acontece, então, ocorre o movimento que se manifesta de maneira recorrente. É uma espécie de movimento circular e, por isso, é chamado de “círculo hermenêutico”. O movimento de circulação é evidente, mas também, ao mesmo tempo, não é um movimento circular fechado, nem de uma espiral, estritamente falando. Porque os momentos, entre os quais a compreensão recíproca, não permanecem os mesmos, em vez disso, eles vão ser revistos e ampliados.

As várias abordagens hermenêuticas tentam lidar com esse problema, cada uma à sua maneira, explica Danner (2006). Para Schleiermacher (1959), a situação do autor deve ser restaurada por reconstrução gramatical e psicológica; para Dilthey (1961) é a possibilidade de compreensão adequada à generosidade de interpretação e; de acordo com Gadamer (1998), o problema surge a partir do zero, porque o interpretador ainda tem que entender de forma diferente por causa de sua situação hermenêutica especial. Diferença hermenêutica surge, por um lado, da "essência consistente” da subjectividade de um “texto" predeterminado e, por outro lado, da objetividade do autor, assim uma abordagem da compreensão está na possibilidade do “espírito objetivo”.

A diferença hermenêutica ocorre no movimento do círculo hermenêutico. Mas isso não pode ser detectado apenas com a aproximação do preconceito e do significado do texto, pontua Danner (2006). O aumento da compreensão não procede em uma linha reta de uma realização progressiva para uma próxima etapa, mas é circular. Esse movimento de compreensão é chamado círculo hermenêutico. Do ponto de vista da abordagem metódica, é importante manter a estrutura circular em mente, porque podem ser necessários, na interpretação, tanto o lado objetivo quanto o lado subjetivo. 


\section{d) Regras hermenêuticas}

Segundo Danner (2006), as regras hermenêuticas podem ser facilmente confundidas com o "preto no branco", mas não devemos esquecer as considerações sistemáticas dos conceitos que estão intimamente ligados: a "compreensão", o "espírito objetivo" e o "círculo hermenêutico". Todos esses conceitos têm o seu lugar, mas não podem fornecer assistência para o processo de compreensão, porque eles não podem ser utilizados como ferramentas metodódicas técnicas para chegar a resultados garantidos.

Na história da hermenêutica, Danner (2006) explica, sempre houve a tentativa de prever regras rigorosas de interpretação, como a hermenêutica teológica e filológica. Por exemplo, o judaísmo, com as sete regras de Hilleis, falava-se na área cristã de regulae ou claves (chaves) e a interpretação de Schleiermacher com o formulado "gramatical” e os "cânones psicológicos".

Na tentativa de colocar regras para a hermenêutica, Bettis (1972, p. 14, apud DANNER, 2006, p. 70, tradução nossa) apresenta os quatro cânones da hermenêutica:

1. "cânone de autonomia hermenêutica do objeto";

2. "cânone de totalidade e relacionamento significativo";

3. "cânone da realidade de compreensão" e;

4. "cânone hermenêutico de correspondência de sentido (adequação do significado de compreensão)".

A hermenêutica de Bettis está fortemente orientada em Schleiermacher e Dilthey e, portanto, é controversa, explica Danner (2006). Mostrar as regras de Bettis é tentar estabelecer regras gerais de interpretação e é difícil e questionável, porque "regras hermenêuticas são destinadas essencialmente aos intérpretes para prestar assistência. Elas são dependentes particularmente da teoria hermenêutica. Por isso, a hermenêutica não é um método de técnica, e está em conexão com a interpretação do texto.” (DANNER, 2006, p. 70, tradução nossa).

Hermenêutica é uma habilidade que exige clareza especial da mente. Porque assim que você pensa sobre um fenômeno, pensa também nos instrumentos metódicos que devem ser ativados a fim de elucidá-los. Rittelmeyer (2013) explicita seis métodos de interpretação hermenêutica de pesquisa: o estrutural, o comparativo, o experimental, o psicológico/mimético, as interpretações analíticas: contextual e cultural. De acordo com o autor, esses métodos evidenciam que a hermenêutica não só se refere a textos, mas há sempre os fenômenos culturais na pesquisa.

Para complementar, Danner (2006, p. 101) indica algumas regras para a compreensão de um texto educacional: 
a) interpretação preliminar: considerar a edição do texto (primeira ou segunda versão), ter sua própria opinião sobre o texto e escrever sobre o sentido geral do texto (a primeira impressão);

b) interpretação de texto imanente: procurar o significado das palavras e relações gramaticais, observar a lógica do texto e observar contradições;

c) interpretação coordenada: observar o contexto do texto e observar a afirmação ou negação das hipóteses.

Vale ressaltar que essas regras não são normativas e taxativas e a compreensão do autor é que norteará os caminhos da compreensão do texto.

Para aqueles que devem se engajar em trabalhos científicos, Danner (2006, p. 103) salienta que até as instruções dos trabalho mais práticos poderiam ser dadas para além das regras hermenêuticas que podem realmente ajudá-lo na interpretação de um texto, por exemplo:

1) Certifique-se de ler todo o texto;

2) Estude o texto sentença a sentença, impressão após impressão; assim, realiza-se pelo menos o esclarecimento de contradições;

3) Leia o texto novamente como um todo;

4) Consulte literatura secundária, possivelmente, um texto semelhante pelo mesmo autor;

5) Trazer algumas reflexões a partir do texto geral;

6) Crie um esboço para todo o texto;

7) Faça uma sinopse para cada seção, como formulação privada e de esclarecimento;

8) Por sua vez, leia todo o texto.

Estas são apenas algumas dicas, sem nenhum esquema rigoroso, explica Danner (2006). No entanto, essas instruções mostram que a análise hemenêutica não é feita a partir de uma leitura rápida.

\section{A hermenêutica na educação}

A hermenêutica é um método que procura interpretar e compreender os fatos e as manifestações da vida cotidiana educacional em que vários fatores estão presentes, como: ações, motivações, sentimentos, desejos individuais, relacionamentos significativos, valores, objetivos, perguntas, instruções, instituições, entre outros. Esses fatores estão inseridos no processo de comunicação que é executado por meio da linguagem, da auto-compreensão, da compreensão estrangeira e da compreensão do significado, do entendimento da tradição, da autoimagem da profissão do educador e da singularidade do indivíduo. 
A hermenêutica parte da compreensão da realidade de tudo o que é humano, que necessita também da compreensão da educação e da formação humana dentro do círculo hermenêutico e isso envolve o contexto mais amplo da realidade educacional. No entanto, é preciso ter consciência de que a hermenêutica é apenas um "método", como uma forma de acesso à realidade educacional, assim como outros métodos. Seu tema são todas as circunstâncias educacionais, desde que possam ser plenamente desenvolvidas apenas pela compreensão, em que a “compreensão” de todos aqueles momentos é desenvolvida na parte teórica. O específico de uma hermenêutica encontrase no sentido da educação e isso a distingue da hermenêutica geral e de outros métodos, porque ela não parte de condições fixas, mas pressupõe e inclui tudo o que é humano.

O entendimento preliminar da educação prática e teórica é responsabilidade principal da hermenêutica, logo, a compreensão do sentido da educação. Por isso, são pontos importantes desse método a compreensão da individualidade dos envolvidos na educação, do significado das realidades educacionais, da responsabilidade da educação e das normas e valores e da reflexão sobre teorias e práticas.

Ao falar em "hermenêutica na educação", surge a pergunta: No que, então, deve consistir a hermenêutica aplicada à educação ou na educação? É relevante, aqui, o que Gadamer (1998) entende por aplicação hemenêutica. Para cada uma dessas várias hermenêuticas, há uma visão diferente. Por exemplo, o advogado vê o seu texto no que diz respeito à justiça, tendo por base, de um lado, o texto legislativo e, de outro lado, o crime específico; ou a Bíblia revela-se, em seu sentido pleno, somente quando manifestada em relação a ela e à sua própria fé.

Mas, então, o educador compreende um como profissional prático ou como um cientista?

\begin{abstract}
Qualquer coisa que ele encontre por escrito, as situações particulares ou realidades sócio-políticas, ele estabelece em termos de educação e que constituem o núcleo de seu entendimento. Agora, faz uma grande diferença se eu entendo a condenação de um criminoso sob o ponto de vista legal da justiça, ou em termos do seu impacto educacional. Entretanto, se a educação é o momento ápice, pelo que entendemos como educadores, é preciso deixar claro o que entendemos por educação. Logicamente, nós chegamos aqui em um beco sem saída: como educação e formação humana podem, finalmente, apenas se transformar em educativa - portanto, ser compreendida em termos de educação e formação humana (DANNER, 2006, p. 98, tradução nossa).
\end{abstract}

Educação é compreendida por cada um de nós, pois faz parte da nossa précompreensão, no sentido mais amplo, pertencente ao contexto, como vemos a nós mesmos, nossas vidas, nosso trabalho, etc. Nesse momento, então, cabe compreender como os educadores conduzem a sua responsabilidade específica, ou seja, os seus objetivos, desejos e vontades diante do ato educacional. A responsabilidade educativa 
é o ponto de partida e o ponto de referência para as atividades educativas, bem como para a reflexão educacional. Essa é a responsabilidade pedagógica, de acordo com Danner (2006). Nesse sentido, não é possível reduzir a educação à explicação e à responsabilidade educativa, mas relacioná-la a um fenômeno contextualizado. Finalmente, pode estar envolvida a compreensão cotidiana na tarefa da hermenêutica, em que a educação é considerada como uma prática. Isso acontece constantemente na realidade educacional, considerada, por sua vez, "não científica”.

Porém, a hermenêutica é vista na educação apenas como um método, contudo, a hermenêutica envolve a compreensão de todas as circunstâncias educacionais, inclusive as desenvolvidas na parte teórica: "a responsabilidade principal da hermenêutica consiste na iluminação do entendimento preliminar da educação prática e teórica, ou seja, o sentido da educação." (DANNER, 2006, p. 118, tradução nossa). A "hermenêutica da realidade educacional" é diferente da hermenêutica no seu sentido estrito, sobretudo pelo fato de que ela não pode começar a partir de condições fixas. Além disso, deve ter um conceito de realidade que pressupõe a inclusão de tudo o que é humano. A relação educativa, entre professor e aluno, é uma qualidade específica das relações humanas, que se revela apenas na compreensão.

A realidade educacional institucionalizada tem de ser interpretada em
termos de sua idéia educacional e sua dimensão histórica. Realidade
educacional é incorporada a fatores sociais, políticos, econômicos
culturais que devem ser evidentes na hermenêutica. A compreensão
da realidade educacional inicia para os teóricos em teoria e para o
praticante em uma atitude ou princípio de abertura. O propósito de
uma hermenêutica da realidade educacional está na percepção da
compreensão como tal, e na transferência de atos de compreensão
elementares para atos de compreensão mais amplos e na interpretação
das condições educacionais individuais no que diz respeito ao seu
contexto. (DANNER, 2006, p. 120, tradução nossa)

De acordo com Danner (2006), para a compreensão da realidade educacional existem alguns momentos que são determinantes na educação e exigem compreensão:

- a individualidade das pessoas envolvidas na educação;

- a dimensão histórica do passado e como agir no presente;

- o significado e a importância de todas as realidades educacionais, reflexões e atividades, incluindo a língua através de sentido educacional e educação, relacionada a um entendimento e auto-compreensão do mundo;

- responsabilidade como o último impulso educativo;

- objetivos educacionais, sem qualquer ação e pensamento pedagógicos seriam impossiveis;

- normas e valores que definem o padrão para os objetivos educacionais. 
Por isso, esse método envolve vários aspectos (Danner, 2006, p. 114-117, tradução nossa):

1) Na realidade educacional, os cientistas educacionais devem procurar entender as crianças e os adolescentes: o que eles fazem, o que os move, o que eles dizem, etc., por meio da compreensão da linguagem, dos gestos, dos valores, das ações, das motivações, ou seja, devem estabelecer o contato direto entre educador e criança e ou adolescente. Isso onsidera e compreende o mundo próprio da criança. Isso significa, portanto, a valorização das crianças e dos adolescentes.

2) E quanto aos atos de entendimento que a criança tem que realizar? A criança deve, primeiro, aprender o conteúdo da compreensão e compreender o próprio entendimento que acontece através das suas primeiras impressões vividas, a quais advêm das mais simples realidades sensoriais e estruturas ensinadas.

3) A relação educativa considera três níveis de compreensão: o da criança, como experimentadora: o do educador, como atuante e elementar e; o contexto humano da relação educativa considerados a partir de uma hermenêutica.

4) A objetivação da realidade educacional institucionalizada requer a compreensão das ideias educacionais, objetivos, normas, desenvolvimentos históricos, projetos pessoais, etc., logo, compreender suas instalações em um processo hermenêutico.

5) A compreensão da realidade educacional, mas também o entendimento dela aponta para além de si mesma, em particular, como mostram as instituições de ensino. Elas são tecidas em um grande número de fatores não educacionais. Isto se refere a políticas culturais e a fatores sociais e econômicos envolvidos na educação.

6) Teoria e prática educacional estão em um relacionamento circular, porque a prática envolve uma pré-concepção (teórica) e porque a teoria pressupõe uma realidade educacional, logo, a teoria ilumina e guia a prática, e praticar a teoria dá sentido.

7) A compreensão da realidade educacional visa também uma atitude que consiste em um desejo de compreender, em que a abertura para o outro é fundamental na situação educacional.

\section{Hermenêutica e as dimensões educacionais na formação humana}

As dimensões educacionais são imprescindíveis para a compreensão da educação e da formação do ser humano. A antropologia educacional histórico-cultural alemã coloca que o ser humano é, em sua natureza, genuinamente educacional, ou seja, sem educação, formação humana, aprendizagem, ensino e socialização, pode se compreender pouco sobre o ser humano. Sendo assim, no processo educacional e formativo do ser humano, as pessoas são muito mais que meros atores escolares. O ser humano é um ser educacional e que, diante de sua necessidade de educação, se educa, se forma, aprende, ensina e socializa. Não é possível reduzir o ser humano apenas ao aspecto da aprendizagem na escola, mas há que se considerar as dimensões básicas da formação 
do ser humano no processo educacional.

Considerando o cenário das dimensões educacionais, o método da hermenêutica é importante para compreender além da dimensão escolar e considerar as dimensões educacionais e as suas conexões, ou seja, considerar que, sem educação, formação humana, aprendizagem, ensino e socialização, pouco se compreende sobre o ser humano. Em Erziehung (educação), o Homem é um ser educacional, ou seja, um ser que educa, além do mais, é a Educação que acontece em casa. Em Lernen (aprender), o Homem é capaz de aprender, enquanto, para a dimensão Bildung (formação humana), o Homem é um ser em formação. Na dimensão Lehren (ensinar), o Homem é um ser que ensina. E, por último, na dimensão Sozialisation (socialização), o Homem é socializante e um ser civilizado. Isso significa considerar o ser humano em seu desenvolvimento e em suas ações.

Ao falar sobre o ser humano, é preciso levar em consideração categorias importantes que constituem e fundamentam a educação: as pessoas aprendem e se desenvolvem, são educadas, por exemplo, educam-se, ensinam os outros e, finalmente, desenvolvem e lidam com questões culturais e sociais, ressaltam Wulf e Zirfas (2014). Embora os termos "aprender" e "formação humana" enfatizem a educação e o ensino mais dirigido ao educando e omitam a atividade intrínseca e a assimilação dos indivíduos, o conceito de socialização inclui transformar essas duas perspectivas, especialmente na duplicação de sua forma transitiva e reflexiva - em suas dimensões sociais e culturais. No entanto, esses termos são aplicados em todas essas disposições educacionais, pois são constitutivos para toda a educação.

Sendo assim, a hermenêutica como método, além contribuir para a compreensão da realidade educacional, oferece a base para a compreensão do sentido da educação e da formação do ser humano ao levar em consideração as dimensões educacionais. A hermenêutica contribui para a compreensão da educação e do processo formativo dos indivíduos, contextualizado e interpretativo, ou seja, a compreensão da realidade educacional e do cotidiano educacional. Isso significa dizer que a hermenêutica conduz à formação humana, pois envolve a complexidade da realidade educacional, como a compreensão das ações, dos comportamentos, dos gestos, dos rituais, das falas, das sensações, entre outros elementos. Através da hermenêutica, complementa Hermann (2002, p. 83), "a educação pode interpretar seu próprio modo de ser, em suas múltiplas diferenças”.

A educação pensada a partir da perspectiva da hermenêutica implica considerar a complexidade da realidade educacional, porque ocorre a análise do processo das dimensões educacionais com a mudança de percepções e interpretações. Essa forma de interpretação e de compreensão contida na proposta hermenêutica não se dá de forma simples e livre de conflitos, explica Gadamer (1998). A hermenêutica desenvolve-se diante de dificuldades e das relações, pois toda interpretação está à 
mercê de arbitrariedades, de análises precipitadas, de opiniões prévias e de conceitos pré-estabelecidos.

A hermenêutica no campo da educação leva a considerar a receptividade e a abertura do sujeito ao contexto que busca interpretar, ressaltando que esse sujeito não é somente um observador, mas um conhecedor da realidade educacional. A hermenêutica auxilia o sujeito na transformação da sua realidade a partir da interpretação e compreensão da sua atual situação, ou seja, significa compreender para mudar. Logo, esse método leva a considerar a diversidade da educação como plural. Todo o processo educativo, quando bem pensado, ou seja, compreendido, por meio de uma interpretação cuidadosa, leva a valorizar a educação como o lugar onde o sujeito compreende a sua formação e a sua realidade educacional.

A dimensão formativa da educação promove o questionamento, a crítica, a reflexão e a ação do sujeito em seu mundo. As relações que se estabelecem entre os sujeitos oportunizam o confronto consigo mesmo, com suas crenças, preconceitos e ideologias, levando ao entendimento dos seus medos, das suas dúvidas, ou seja, a compreensão dos acontecimentos da realidade educacional. A partir dessa compreensão, propõe-se uma nova construção do ser.

\section{Considerações finais}

A hermenêutica como método expande as perspectivas para a compreensão da realidade educacional. Desse modo, os atos de interpretar e compreender facetas da realidade educacional expõem elementos imprescindíveis do processo educacional, como formação humana, aprendizagem, ensino e socialização. Isso leva a considerar os vários fatores presentes, como: ações, motivações, sentimentos, desejos, individuais, relacionamentos significativos, valores, objetivos, perguntas, instruções, instituições, entre outros.

\footnotetext{
A possibilidade compreensiva da hermenêutica permite que a educação torne esclarecidas para si mesma suas próprias bases de justificação, por meio do debate a respeito das racionalidades que atuam no fazer pedagógico. Assim, a educação pode interpretar o seu próprio modo de ser, em suas múltiplas diferenças. (HERMANN, 2002, p. 83)
}

Para esse método, então, torna-se fundamental a compreensão da hermenêutica. A hermenêutica é a arte da interpretação de compreender o texto que ocorre num movimento circular, envolvendo tanto o lado objetivo quanto o subjetivo. Esses elementos em constante movimento circular abrem horizontes para a pesquisa em educação, porque envolve teoria, ação, reflexão e mundo da vida. Por isso, é importante considerar os seus quatro conceitos: a compreensão, a responsabilidade da compreensão, o círculo hermenêutico e as regras da hermenêutica. Esses conceitos complementamse no decorrer da pesquisa hermenêutica e da interpretação e compreensão do texto. 
O conceito central da hermenêutica é a "compreensão", no qual estão intimamente ligados: a "compreensão", o "espírito objetivo" e o "círculo hermenêutico".

Esses princípios interligados com a educação partem da compreensão de que tudo é humano, o que implica, também, a compreensão da educação e da formação humana dentro do círculo hermenêutico, e isso envolve o contexto mais amplo da realidade educacional. O específico de uma hermenêutica encontra-se no sentido da educação, porque ela não parte de condições fixas, mas pressupõe e inclui tudo o que é humano. Por isso, as dimensões educacionais são imprescindíveis para a compreensão da educação e da formação do ser humano.

Considerar também as dimensões básicas educacionais Erziehung (educação), Lernen (aprender), Bildung (formação humana), Lehren (ensinar), e Sozialisation (socialização) é importante para expandir o olhar sobre as problemáticas educacionais. Diferentemente, no Brasil, como explica Vieira (2017), as pesquisas em educação privilegiam a escola e os elementos que envolvem a escola, como: o processo de escolarização; a aprendizagem da leitura e escrita; o ensinar e o aprender; e os papéis do professor e do aluno. Considerar as cinco dimensões educacionais em outros espaços é levar em consideração o desenvolvimento e as ações do ser humano em sua historicidade e culturalidade. Isso implica tornar relevantes os estudos para além do âmbito escolar, como, por exemplo, a condição humana na educação, em sua natureza, em sua história e em sua cultura. Considerar também a performance, a corporalidade, os gestos e a mimesis, é levar em conta que a educação e o processo educacional são naturalizados e culturalizados, com ação e reflexão. Pode-se concluir, então, que a hermenêutica é importante para a compreensão da realidade educacional e, desse modo, é de fundamental importância para a construção de novos sentidos para a ação educativa e para a pesquisa em educação.

\section{Referências}

DANNER, H. Hermeneutik. In: DANNER, H. Methoden geisteswissenschaftlicher Pädagogik. Einführung in Hermeneutik, Phänomenologie und Dialektik. München: Ernst Reinhardt, GmbH \& Co KG, Verlag, München, 2006. p. 34-120.

DILTHEY, W. Gesammelte Schriften. Band VII: Der Aufbau der geschichtlichen Welt in den Geisteswissenschaften. 3. ed. Stuttgart: Vandenhoeck \& Ruprecht, 1961.

. A compreensão dos outros e das suas manifestações de vida. Lisboa: Fundação Calouste Gulbenkian, 1984.

. Introduction to the Human Sciences. New Jersey: Princeton University Press, 1989. (Selected Works, v. I). 
FLICK, U. Mapping the Field. In: FLICK, U. The SAGE Handbook of Qualitative Data Analysis. Sage: London, 2014. p. 3-18.

FLICK, U.; KARDORFF, E.; STEINKE, I. What is Qualitative Research? An Introduction to the Field. In: FLICK, U.; KARDORFF, E.; STEINKE, I. (Orgs.) A companion to Qualitative Research. Translated by Bryan Jenner. Sage Publications: London, Thousand Oaks, New Delhi, 2004. p. 3-11.

GADAMER, H. G. Verdade e Método; traços fundamentais de uma hermenêutica filosófica. 2. ed. Petrópolis: Editora Vozes, 1998.

HERMANN, N. Hermenêutica e Educação. Rio de Janeiro: DP\&A, 2002.

MAYRING, P. Einführung in die qualitative Sozialforschung: eine Anleitung zum qualitativen Denken. Weinheim: Beltz Verlag, 2002.

RITTELMEYER, C. Methoden hermeneutischer Forschung. In: FRIEBERTSHÄUSER, B.; LANGER, A.; PRENGEL, A. (Hrsg.) Handbuch - Qualitative Forschungsmethoden in der Erziehungswissenchaft. Weinheim: BeltzJuventa, 2013. p. 235-248.

RITTELMEYER, C.; PARMENTIER, M. Einführung in die pädagogische Hermeneutik. Darmstadt: WBG, 2006.

SCHLEIERMACHER, F. Hermeneutik. Heidelberg: Winter, 1959.

VIEIRA, K. A. L. Antropologia da Educação: levantamento, análise e reflexão no Brasil. Curitiba: CRV, 2017.

WELLER, Wivian. A hermenêutica como método empírico de investigação. In: $30^{a}$ Reunião Anual da ANPEd, 2007, Caxambu. 30a Reunião Anual da ANPEd, 2007. p. $1-16$.

WULF, C.; ZIRFAS, J. Homo educandus - Eine Einleitung in die Pädagogische Anthropologie. In: WULF, C.; ZIRFAS, J. (Hrsg.) . Berlin: Springer, 2014. p. 9 - 21.

Recebido em: 08/03/2018

Aprovado em: 22/05/2019 